\title{
Analysis of Factors Contributing to Postoperative Spinal Instability after Lumbar Decompression for Spinal Stenosis
}

\author{
Joo Chul Yang, Sung Gon Kim, Tae Wan Kim, Kwan Ho Park \\ Department of Neurosurgery, VHS Medical Center, Seoul, Korea
}

\begin{abstract}
Objective: Decompressive laminectomy is one of the most commonly used surgical methods for the treatment of spinal stenosis. We retrospectively examined the risk factors that induce spinal instability, including slippage (spondylolisthesis) and/or segmental angulation after decompressive laminectomy on the lumbar spine.

Methods: From January 1, 2006 to June 30, 2010, 94 consecutive patients underwent first-time single level decompressive laminectomy without fusion and discectomy. Of these 94 patients, 42 with a follow-up period of at least 2 years were selected. We measured the segmental angulation and slippage in flexion and extension dynamic lumbar radiographs. We analyzed the following contributing factors to spinal instability: age/sex, smoking history, disc space narrowing, body mass index (kg/ $\mathrm{m}^{2}$ ), facet joint tropism, effect of the lordotic angle on lumbar spine, asymmetrical paraspinal muscle volume, and surgical method and level.

Results: Female patients, normal lordotic angle, and asymmetrical paraspinal muscle volume were factors more significantly associated with spondylolisthesis ( $p$-value $=0.026,0.015,<0.01)$. Statistical results indicated that patients with facet tropism were more likely to have segmental angulation ( $p$-value $=0.046$ ). Facet tropism and asymmetry of paraspinal muscle volume were predisposing factors to spinal instability ( $p$-value $=0.012,<0.01$ ).

Conclusion: Facet joint tropism and asymmetry of paraspinal muscle volume are the most important factors associated with spinal instability; therefore, careful follow-up after decompressive laminectomy in affected patients is necessary.
\end{abstract}

Key Words: Spinal stenosis $\cdot$ Facet tropism $\cdot$ Paraspinal muscle $\cdot$ Instability

\section{INTRODUCTION}

Lumbar spinal stenosis is recognized with increasing frequency as a cause of low back pain and lower extremity pain, and is a degenerative disease that most often requires surgery in elderly patients. Laminectomy is a commonly used surgical method. The occurrence of spinal stenosis may increase with advancing age. However, approximately one-third of surgically treated patients are not satisfied with the outcome of surgerys $^{7,17)}$. Decompressive laminectomy appears to reduce pain and restore function in many patients, and the procedure is probably associated with an acceptably low rate of complications $^{22)}$. Patients with symptomatic spinal stenosis treated surgically maintain substantially greater improvement in pain and

- Received: July 15, 2013 • Revised: September 11, 2013

- Accepted: September 13, 2013

Corresponding Author: Tae Wan Kim, MD

Department of Neurosurgery, VHS Medical Center, 53 Jinhwangdo-ro,

61-gil, Gangdong-gu, Seoul 134-791, Korea

Tel: +82-2-2225-1363, FAX: +82-2-2225-4152

E-mail: euro3399@naver.com function over a 4-year period than those treated nonsurgically ${ }^{23)}$. However, the optimal surgical treatment method is not clear. Maintaining spinal stability is important after surgical treatment, although the occurrence of spinal instability is not correlated with clinical outcomes ${ }^{6}$. The purpose of this study was to investigate the factors that contribute to spondylolisthesis and segmental angulation.

\section{MATERIALS AND METHODS}

From January 1, 2006 to June 30, 2010, 94 consecutive patients underwent first-time single level decompressive laminectomy without fusion and discectomy of the lumbar spine. We excluded patients in whom revision surgery or other lumbar surgical procedures had been performed. Patients with preoperative instability were also excluded. Decompressive laminectomy was performed with preservation of the facet joint. We selected 42 patients with a follow-up period of at least 2 years. We analyzed the following contributing factors to spinal instability: age/sex, smoking history, osteoporosis on bone mineral density, disc space narrowing, previous surgery on an orthopedic joint (hip, knee, or ankle), body mass index 
$\left(\mathrm{kg} / \mathrm{m}^{2}\right)$, facet joint tropism, effect of the lordotic angle on the lumbar spine, paraspinal muscle volume asymmetry, and surgical method and level. Preoperative and postoperative radiographic examinations were performed in 42 patients. Using dynamic lumbar radiographs, we measured the preoperative and postoperative segmental angulation and degree of slippage in flexion and extension. To determine the amount of sagittal rotation angle, lines were drawn between the anterior and posterior borders of the end plate on flexion-extension lateral views. The sum of each angle between two lines was defined as the sagittal rotation angle in the segment ${ }^{5)}$. More than $3 \mathrm{~mm}$ of slippage was defined as postoperative spondylolisthesis. More than $15^{\circ}$ of sagittal rotation angle was defined as segmental angulation in the laminectomized segment ${ }^{5,6}$. Spinal instability was thought to have occurred if any one of these factors was observed. There was no postoperative mortality and neurologic deterioration. Three patients underwent reoperation. One of patient underwent discectomy and the other had subtotal laminectomy because of canal restenosis. Only 1 patient showed signs of symptomatic spinal instability. Therefore, this patient underwent spinal fusion with instrumentation.

\section{Patient Characteristics}

The 42 patients were 38 men and 4 women. The mean age was 67.5 years (range, 38-81 years). There were 18 patients who smoked and 24 who did not; only 2 patients with osteoporosis and had undergone preoperative orthopedic joint surgery. Because of the small number of patients, statistical analysis was not performed. The body mass index (BMI) was calculated and divided by 25 .

\section{Radiologic Assessment}

The lordotic angle was determined at the intersection of the lines at the level of the inferior plateau of T12 and the superior plateau of S1, Cobb's method, in the neutral position. Normal lordotic angle was defined between $31^{\circ}$ and $50^{\circ}$. Facet joint tropism is defined as an asymmetry of the left and right vertebral facet joint angles, with 1 joint having a more sagittal orientation than the other ${ }^{10,15)}$. We regarded facet tropism as a $>10^{\circ}$ difference in the facet joint angles between the right and left $\operatorname{sides}^{10)}$. The volume of the paraspinal muscle was defined as the cross-sectional area, thickness, and width of the multifidus muscle on the magnetic resonance imagingslice parallel to the disc space on the surgical level ${ }^{4,19)}$. The volume of the multifidus muscle was defined by manual tracing of the fascial boundary of the muscles at both sides by using m-view image-analysis software (5.4 version, Marotech Inc.). Paraspinal muscle volume asymmetry was defined as a $>10 \%$ difference between the right and left sides.

\section{Surgical Method and Level}

The surgical method comprised subtotal laminectomy, bilateral partial hemilaminectomy, and unilateral partial hemilaminectomy (including bilateral decompression). Thirty-six patients were operated upon at the L 4-5 level.

\section{Statistical Analysis}

Statistical analyses were performed using Fisher's exact test to compare the occurrence. A p value of less than 0.05 was considered significant.

\section{RESULTS}

\section{Occurrence of Spondylolisthesis}

Spondylolisthesis occurred in 9 patients (21.4\%). Six patients were men and 3 were women. Female patients were more prevalent than male patients $(75.0 \%$ and $15.8 \%$, respectively). Spondylolisthesis was more common in patients aged $>65$ years $(27.3 \%$ versus $15.0 \%)$. Patients who smoked and those with obesity (body mass index $>25$ ) had more prevalent spondylolisthesis $(27.8 \%$ versus $16.7 \%$ in those who smoked and those who did not respectively, and $25.0 \%$ versus $18.2 \%$ in obese and nonobese patients, respectively). Post-operative spondylolisthesis developed in all patients with a normal lordotic angle and those who underwent laminectomy at the $\mathrm{L}$ 4-5 level. Patients with facet joint tropism and disc space narrowing had more prevalent spondylolisthesis (33.3\% and 16.7 $\%$ in those with and without facet joint tropism, respectively; $36.4 \%$ versus $16.1 \%$ in those with and without disc space narrowing, respectively). Patients with asymmetrical of paraspinal muscle volume had statically more frequent spondylolisthesis (p-value $<0.01$ ). The patients who underwent subtotal laminectomy had spondylolisthesis more often than bilateral partial hemilaminectomy and unilateral laminectomy (27.3\%, 25.0\%, and 8.3\%, respectively). However, all factors were not found to be correlated with the occurrence of spondylolisthesis. Female patients and those with a normal lordotic angle more often had spondylolisthesis ( $\mathrm{p}$-value $=0.026$, and 0.015 , respectively) (Table 1).

\section{Occurrence of Segmental Angulation}

Segmental angulation occurred in 6 male patients (14.3\%). The patients aged $<65$ years were more likely to have segmental angulation $(13.6 \%$ versus $15.0 \%$ in older and younger pa- 
tients, respectively). Segmental angulation was more prevalent in those who smoked $(16.7 \%$ versus $12.5 \%$ in patients who smoked and those who did not, respectively). Obese patients and those with a normal lordotic angle had segmental angulation less often $(10.0 \%$ versus $18.2 \%$ in obese and nonobese patients, respectively; $7.1 \%$ versus $14.3 \%$ in those with a normal and abnormal lordotic angle, respectively). Patients with facet joint tropism had segmental angulation more often (33.3 $\%$ versus $6.7 \%$ in those with or without facet joint tropism, respectively). Patients with asymmetrical paraspinal muscle volume had segmental angulation more frequently $(20.0 \%$ versus $12.5 \%$ in those with/without asymmetry), but the difference was not statistically significant. Patients who underwent subtotal laminectomy had segmental angulation more often than bilateral partial hemilaminectomy and unilateral laminectomy $(18.2 \%, 12.5 \%$, and $8.3 \%$, respectively). Patients with facet joint tropism were more likely to have segmental angulation statistically (p-0.046) (Table 2).

Table 1. Prognostic factors relating to occurrence of spondylolisthesis

\begin{tabular}{|c|c|c|c|c|}
\hline & & $\begin{array}{l}\text { Spondylolisthesis } \\
(\mathrm{n}=9)\end{array}$ & $\begin{array}{l}\text { Non-spondylolisthesis } \\
(\mathrm{n}=33)\end{array}$ & p-value \\
\hline \multirow[t]{2}{*}{ Sex } & Male & 6 & 32 & 0.026 \\
\hline & Female & 3 & 1 & \\
\hline \multirow[t]{2}{*}{ Age } & More than 65 & 6 & 16 & 0.278 \\
\hline & Less than 65 & 3 & 17 & \\
\hline \multirow[t]{2}{*}{ Smoking } & $(+)$ & 5 & 13 & 0.311 \\
\hline & $(-)$ & 3 & 20 & \\
\hline \multirow[t]{2}{*}{ Body mass index } & More than 25 & 5 & 15 & 0.319 \\
\hline & Less than 25 & 4 & 18 & \\
\hline \multirow[t]{2}{*}{ Lordotic angle } & $31^{\circ}-50^{\circ}$ & 9 & 19 & 0.015 \\
\hline & $31^{\circ}<$ or $>50^{\circ}$ & 0 & 14 & \\
\hline \multirow[t]{2}{*}{ Facet tropism } & $(+)$ & 4 & 8 & 0.216 \\
\hline & $(-)$ & 5 & 25 & \\
\hline \multirow[t]{2}{*}{ Disc space narrowing } & $(+)$ & 4 & 7 & 0.163 \\
\hline & $(-)$ & 5 & 26 & \\
\hline \multirow[t]{2}{*}{ Asymmetry of paraspinal muscle } & $(+)$ & 6 & 4 & $<0.001$ \\
\hline & $(-)$ & 3 & 29 & \\
\hline \multirow[t]{2}{*}{ Level } & L4-5 & 9 & 27 & 0.211 \\
\hline & L2-3, 3-4, L5-S1 & 0 & 6 & \\
\hline \multirow[t]{2}{*}{ Operative method } & Subtotal laminectomy & 6 & 16 & 0.278 \\
\hline & Bilateral or unilateral partial laminectomy & 3 & 17 & \\
\hline
\end{tabular}

Table 2. Prognostic factors relating to occurrence of segmental angulation

\begin{tabular}{|c|c|c|c|c|}
\hline & & Angulation $(\mathrm{n}=6)$ & Non-angulation $(n=36)$ & p-value \\
\hline \multirow[t]{2}{*}{ Sex } & Male & 6 & 32 & 0.526 \\
\hline & Female & 0 & 4 & \\
\hline \multirow[t]{2}{*}{ Age } & More than 65 & 3 & 19 & 0.620 \\
\hline & Less than 65 & 3 & 17 & \\
\hline \multirow[t]{2}{*}{ Smoking } & $(+)$ & 3 & 15 & 0.519 \\
\hline & $(-)$ & 3 & 21 & \\
\hline \multirow[t]{2}{*}{ Body mass index } & More than 25 & 2 & 18 & 0.379 \\
\hline & Less than 25 & 4 & 18 & \\
\hline \multirow[t]{2}{*}{ Lordotic angle } & $31^{\circ}-50^{\circ}$ & 2 & 26 & 0.407 \\
\hline & $31^{\circ}<$ or $>50^{\circ}$ & 2 & 12 & \\
\hline \multirow[t]{2}{*}{ Facet tropism } & $(+)$ & 4 & 8 & 0.046 \\
\hline & $(-)$ & 2 & 28 & \\
\hline \multirow[t]{2}{*}{ Disc space narrowing } & $(+)$ & 1 & 10 & 0.497 \\
\hline & $(-)$ & 5 & 26 & \\
\hline \multirow[t]{2}{*}{ Asymmetry of paraspinal muscle } & $(+)$ & 2 & 8 & 0.626 \\
\hline & $(-)$ & 4 & 26 & \\
\hline \multirow[t]{2}{*}{ Level } & L4-5 & 5 & 31 & 0.629 \\
\hline & L2-3, 3-4, L5-S1 & 1 & 5 & \\
\hline \multirow[t]{2}{*}{ Operative method } & Subtotal laminectomy & 4 & 18 & 0.379 \\
\hline & Bialteral or unilateral partial laminectomy & 2 & 18 & \\
\hline
\end{tabular}




\section{Occurrence of Spinal Instability (Spondylolisthesis} and/or segmental angulation)

Spinal instability occurred in 15 patients (35.7\%). Twelve patients were men and 3 patients were women. Spinal instability occurred more often in patients aged $>65$ years $(40.9 \%$ versus $30.0 \%$ ), and was more prevalent in those who smoked (44.4\% versus $29.2 \%)$. Spinal instability was more prevalent in patients with facet joint tropism and disc space narrowing $(66.7 \%$ versus $23.3 \%$, and $45.5 \%$ versus $32.3 \%$, respectively). Spinal instability was also more prevalent in with asymmetrical paraspinal muscle volume $(\mathrm{p}-<0.01)$. Patients who underwent subtotal laminectomy had spinal instability that occurred more often than bilateral partial hemilaminec- tomy and unilateral laminectomy $(45.5 \%, 37.5 \%$, and $16.7 \%$, respectively). Facet joint tropism was the only predisposing factor to spinal instability statistically (p-0.012) (Table 3).

\section{DISCUSSION}

Lumbar spinal stenosis is major reason for back pain and claudication with advancing age. The natural course of lumbar spinal stenosis fluctuates and is not necessarily progressive. Management of this condition is by conservative treatment and decompression using various methods. Positive results for both treatments were maintained for 2-4 years ${ }^{23)}$.

Bilateral and unilateral laminotomy allowed adequate and safe decompression of lumbar stenosis, resulting in a highly significant reduction of symptoms and disability, and im- proved health-related quality of life ${ }^{21)}$. Total laminectomy is preferable for patients with severe degenerative stenosis or marked degenerative spondylolisthesis ${ }^{14)}$. Posterior decompression without fusion with instrumentation is safe and effective ${ }^{11,12,13,18)}$, but approximately one-third of surgically treated patients were not satisfied with the outcome ${ }^{7}$. Decompressive laminectomy alone rather than fusion can be considered, if there is no overt instability for patients with lumbar spinal stenosis at $\geq 2$ levels ${ }^{18)}$. Bilateral laminotomy was found to be associated with significantlyimproved outcome parameters compared to those of unilateral laminotomy and laminectomy during a minimum follow-up period of 12 months ${ }^{21}$.

Regular analgesic use for $\leq 12$ months and cessation of smoking led to good postoperative functional improvement. Age $\leq 75$ years and no previous lumbar surgery were predictive of good postoperative outcomes ${ }^{1)}$. Multiple laminectomy was thought to be a risk factor for poor outcome ${ }^{5 \text { ). Patients }}$ with a $<4$-year preoperative duration of symptoms, no preoperative back pain,and absence of other conditions affecting walking tended to have better surgical outcomes ${ }^{9}$. Leg pain lasting more than 2 years and low preoperative function predicted poor clinical outcome. A narrow dural sac area was predictive of greater improvement in terms of back pain ${ }^{17}$. One study showed no definite clinical or radiological factors that preoperatively predict patients at risk for poor outcomes ${ }^{3}$.

Low bone mineral density, small intervertebral discs and absence of osteophytes could predict the possible development of instability following laminectomy ${ }^{2}$. A sagittal rotation angle $>10^{\circ}$ would indicate the possibility of a poor outcome ${ }^{5}$.

Table 3. Prognostic factors relating to occurrence of spinal instability

\begin{tabular}{|c|c|c|c|c|}
\hline & & Instability $(\mathrm{n}=15)$ & Non-instability $(\mathrm{n}=27)$ & p-value \\
\hline \multirow[t]{2}{*}{ Sex } & Male & 12 & 26 & 0.121 \\
\hline & Female & 3 & 1 & \\
\hline \multirow[t]{2}{*}{ Age } & More than 65 & 9 & 13 & 0.340 \\
\hline & Less than 65 & 6 & 14 & \\
\hline \multirow[t]{2}{*}{ Smoking } & $(+)$ & 8 & 10 & 0.242 \\
\hline & $(-)$ & 7 & 17 & \\
\hline \multirow[t]{2}{*}{ Body mass index } & More than 25 & 7 & 13 & 0.591 \\
\hline & Less than 25 & 8 & 14 & \\
\hline \multirow[t]{2}{*}{ Lordotic angle } & $31^{\circ}-50^{\circ}$ & 11 & 17 & 0.095 \\
\hline & $31^{\circ}<$ or $>50^{\circ}$ & 2 & 12 & \\
\hline \multirow[t]{2}{*}{ Facet tropism } & $(+)$ & 8 & 4 & 0.012 \\
\hline & $(-)^{\prime}$ & 7 & 23 & \\
\hline \multirow[t]{2}{*}{ Disc space narrowing } & $(+)$ & 5 & 6 & 0.333 \\
\hline & $(-)$ & 10 & 21 & \\
\hline \multirow[t]{2}{*}{ Asymmetry of paraspinal muscle } & $(+)$ & 8 & 2 & $<0.001$ \\
\hline & $(-)$ & 7 & 25 & \\
\hline \multirow[t]{2}{*}{ Level } & L4-5 & 14 & 22 & 0.287 \\
\hline & L2-3, 3-4, L5-S1 & 1 & 5 & \\
\hline \multirow[t]{2}{*}{ Operative method } & Subtotal laminectomy & 10 & 12 & 0.145 \\
\hline & Bialteral or unilateral partial laminectomy & 5 & 15 & \\
\hline
\end{tabular}


Occurrence or progression of instability seems to be associated with the resection of the posterior spinal elements rather than the disc ${ }^{6}$. Instability is affected by the surgical procedure rather than the follow-up period ${ }^{6}$. In our study, the patients who underwent subtotal laminectomy were more likely to experience spinal instability than bilateral and unilateral laminectomty, but the difference was not statistically significant. The incidence of instability at the surgical level in patients aged $<60$ years was significantly higher in cases of wide laminectomy than in those of partial laminectomy. A partial laminectomy is preferred to prevent postoperative instability. Unilateral laminectomy for bilateral decompression can result in satisfactory decompression and tolerable clinical outcome ${ }^{8)}$. The significance of postoperative spondylolisthesis is not entirely clear. Postoperative spondylolisthesis could be avoided by a more limited decompression, or by fusion of the segment at the time of surgery. Sagittal facet joint orientation and a reduced coronal facet joint dimension before decompression are associated with development of postoperative spondylolisthesis. Furthermore, there is an association between wellmaintained disc height and postoperative spondylolisthesis ${ }^{16}$. In vitro, segmental instability is less likely to develop in the presence of posterior complex integrity than in a lumbar spine with a destroyed anchoring point for the supraspinous ligament. Under flexion motion, intervertebral displacement of the laminectomy at decompression level L4-L5 was greater than that in intact or bilateral laminotomy specimens in vitro ${ }^{20}$. In our study, the patient who underwent discectomy during the follow-up period had subtotal laminectomy at L4-5.

Preservation of paraspinal muscles and decreased incidence of injury to muscle is the most important factors associated with a positive effect on long-term clinical outcome ${ }^{4,19}$. Our study showed that asymmetry of the paraspinal muscles also influenced the occurrence of postoperative instability.

Facet tropism was not associated with the occurrence of facet joint osteoarthritis or degenerative spondylolisthesis ${ }^{10}$. Facet tropism was also not associated with postoperative instability $^{2,10)}$. However, our study demonstrated that facet tropism was associated with segmental angulation, not spondylolisthesis.

The retrospective study design, relatively small number of patients, and short follow-up periods can be considered limitations of our study. More than one-third patients progress to spinal instability, but only 1 patient underwent spinal fusion. Therefore, the relationship between postoperative spinal instability and the related symptoms should be evaluated.

\section{CONCLUSION}

Facet joint tropism and asymmetry of paraspinal muscle volume are the most important factors affecting spinal instability. Patients with facet joint tropism and asymmetrical paraspinal muscle volume should be followed up more carefully than other patients after decompressive laminectomy.

\section{REFERENCES}

1. Aalto T, Sinikallio S, Kroger H, Viinamaki H, Herno A, Leinonem V, et al: Preoperative predictors for good postoperative satisfaction and functional outcome in lumbar spinal stenosis surgery-A prospective observational study with a two- year follow-up. Scand J Surg 101(4):255-260, 2012

2. Bisschop A, van Royen BJ, Mullender MG, Paul CP, Kingma I, Jiya TU, et al: Which factors prognosticate spinal instability following lumbar laminectomy? Eur Spine J 21:2640-2648, 2012

3. Fox MW, Onofrio BM, Hanssen AD: Clinical outcomes and radiological instability following decompressive lumbar laminectomy for degenerative spinal stenosis: a comparison of patients undergoing concomitant arthrodesis versus decompression alone. J Neurosurg 85:793-802, 1996

4. Hyun SJ, Kim YB, Kim YS, Park SW, Nam TK, Hong HJ, et al: Postoperative changes in paraspinal muscle volume: Comparison between paramedianinterfascial and midline approaches for lumbar fusion. J Korean Med Sci 22:646-651, 2007

5. Iguchi T, Kurihara A, Nakayama J, Sato K, Kurosaka M, Yamasaki K: Minimum 10-year outcome of decompressive laminectomy for degenerative lumbar spinal stenosis. Spine (Phila Pa 1976) 25(14):1754-1759, 2000

6. Iida Y, Kataoka O, Sho T, Sumi M, Hirose T, Bessho Y, et al: Postoperative lumbar spinal instability occurring or progressing secondary to laminectomy. Spine (Phila Pa 1976) 15:11861189, 1990

7. Javid MJ, Hadar EJ: Long-term follow-up review of patients who underwent laminectomy for lumbar stenosis: a prospective study. J Neurosurg 89:1-7, 1998

8. Ji YC, Kim YB, Hwang SN, Park SW, Kwon JT, Min BK: Efficacy of unilateral laminectomy for bilateral decompression in elderly lumbar spinal stenosis. J Korean Neurosurg Soc 37: 410-415, 2005

9. Jonsson B, Annertz M, Sjoberg C, Stromqvist B: A prospective and consecutive study of surgically treated lumbar spinal stenosis. Spine (Phila Pa 1976) 22(24):2938-2944, 1997

10. Kalichman L, Suri P, Guermazi L, Li L, Hunter DJ: Facet orientation and tropism: associations with facet joint osteoarthritis and degeneratives. Spine (Phila Pa 1976) 34(16):579-585, 2009

11. Kaymaz M, Borcek AO, Emmez H, Durdag E, Pasaoglu A: Effectiveness of single posterior decompressive laminectomy in symptomatic lumbar spinal stenosis: a retrospective study. Turk Neurosurg 22(4):430-434, 2012

12. Kim DW, Kim SB, Kim YS, Ko Y, Oh SH, Oh SJ: Surgical treatment of lumbar spinal stenosis in geriatric population: Is it risky? J Korean Neurosurg Soc 38:107-110, 2005

13. MicankovaAdamova B, Vohanka S, Dusek L, Jarkovsky J, Bednarik J: Prediction of long-term clinical outcome in patients with lumbar spinal stenosis. Eur Spine J 21:2611-2619, 2012

14. Ofluoglu AE, Karasu A, Ekinci B, Toplamaoglu H: The effect 
of laminectomy on instability in the management of degenerative lumbar stenosis surgery: a retrospective radiographic assessment. Turk Neurosurg 17(3):178-182, 2007

15. Paik JY, Yoon SM, Yoo CJ: A comparison of clinical outcomes between decompressive laminectomy alone and with arthrodesis in lumbar single level spinal stenosis. Korean J Spine 7(1):17-23, 2010

16. Postacchini F, Cinotti G, Perugia D, Gumina S: The surgical treatment of central lumbar stenosis. Multiple laminotomy compared with total laminectomy. J Bone Joint Surg Br 75(3):386392, 1993

17. Resnick DK, Choudhri TF, Dailey AT, Groff MW, Khoo L, Matz PG, et al: Guidelines for the performance of fusion procedures for degenerative disease of the spine. Part 10: fusion following decompression in patients with stenosis without spondylolisthesis. J Neurosurg Spine 2:686-691, 2005

18. Robertson PA, Grobler LJ, Novotny JE, Katz JN: Postoperative spondylolisthesis at L 4-5. The role of facet joint morphology. Spine (Phila Pa 1976) 18(11):1483-1490, 1993

19. Seo JH, Park G, Ju CI, Kim SW, Lee SM: Radiological analysis of symptomatic complications after bilateral laminotomy for lumbar spinal stenosis. Korean J Spine 9(1):18-23, 2012

20. Sigmundsson FG, Kang XP, Jonsson B, Stromqvist B: Prognostic factors in lumbar spinal stenosis surgery. A prospective study of image- and patient-related factors in 109 patients who were operated on by decompression. Acta Orthop 85(5):536-542, 2012

21. Son S, Kim WK, Lee SG, Park CW, Lee K: A comparison of the clinical outcomes of decompression alone and fusion in elderly patients with two-level or more lumbar spinal stenosis. J Korean Neurosurg Soc 53:19-25, 2013

22. Suwa H, Hanakita J, Ohshita N, Gotoh K, Matsuoka N, Morizane A: Postoperative changes in paraspinal muscle thickness after various lumbar back surgery procedure. Neurol Med Chir (Tokyo) 40:151-155, 2000

23. Tai CL, Hsieh PH, Chen WP, Chen LH, Chen WJ, Lai PL: Biomechanical comparison of lumbar spine instability between laminectomy and bilateral laminotomy for spinal stenosis syndrome-an experimental study in porcine model. BMC Musculoskelet Disord 9:84-92, 2008 